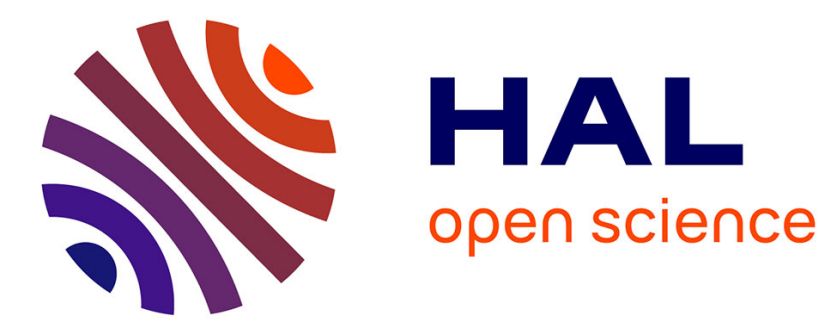

\title{
Astrophysical cause of tectonics
}

M Omerbashich

\section{To cite this version:}

M Omerbashich. Astrophysical cause of tectonics. 2016. hal-01291138v2

\section{HAL Id: hal-01291138 \\ https://hal.science/hal-01291138v2}

Preprint submitted on 22 Jun 2016

HAL is a multi-disciplinary open access archive for the deposit and dissemination of scientific research documents, whether they are published or not. The documents may come from teaching and research institutions in France or abroad, or from public or private research centers.
L'archive ouverte pluridisciplinaire HAL, est destinée au dépôt et à la diffusion de documents scientifiques de niveau recherche, publiés ou non, émanant des établissements d'enseignement et de recherche français ou étrangers, des laboratoires publics ou privés.

\section{(1)}

Distributed under a Creative Commons Attribution - NonCommercial - NoDerivatives 44.0 


\section{Cover art}

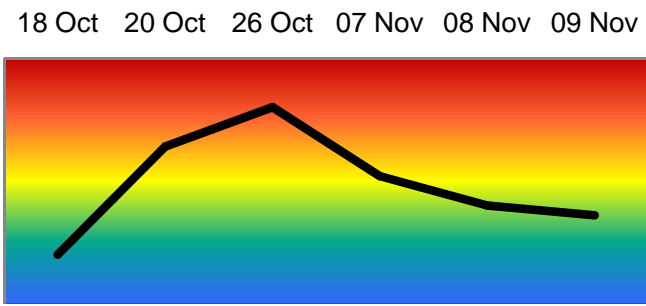

2015

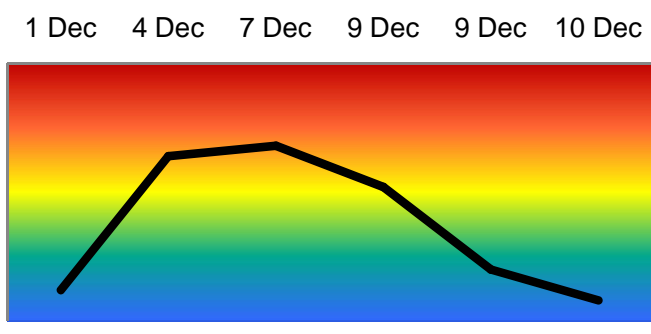

2015
17 Nov 18 Nov 24 Nov 26 Nov 27 Nov 28 Nov 29 Nov $M_{w}$

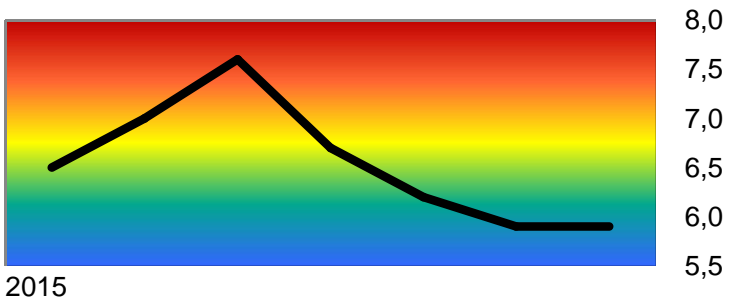

27 May 27 May 28 May 28 May 31 May 31 May 31 May $M_{w}$

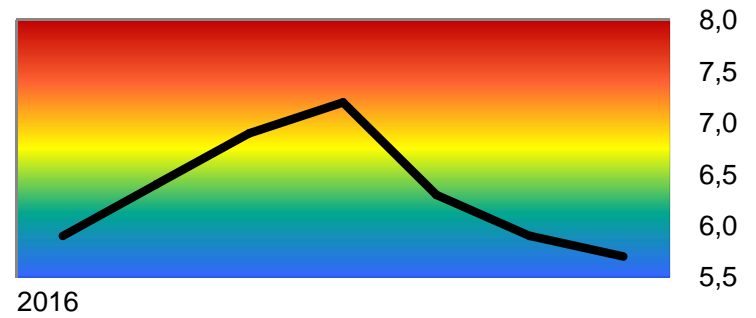

Up-Peak-Down seismic pattern: strength of global M6+ (tectonic) earthquakes peaks under Earth's astronomical alignments to 2 heavenly bodies lasting $3+$ days, enabling negative seismic forecast (forecasting in terms of absence of M6+ seismicity). Discovery shows that tectonics is controlled by astrophysical phenomena instead of geophysical as previously believed. Composite: the pattern gets better resolved with increase in occurrence of $\mathbf{M}_{\mathbf{w}} \mathbf{6 . 3 +}$ earthquakes: top left panel, during JupiterVenus-Earth alignment of October-November 2015; top right, during Venus-Earth-Uranus alignment of November 2015; bottom left, during Earth-Sun-Saturn alignment of December 2015; bottom right, during Earth-Sun-Venus alignment of May-June 2016. 


\title{
Astrophysical cause of tectonics
}

\author{
Mensur Omerbašić ${ }^{1}$
}

Tectonic earthquakes, of Mw(6 $\pm 5 \%)+$, are found forming a strengthening-peaking-waning pattern distinguishable from respectively quiescent times so well that the pattern means discovery of a universal natural mechanism that necessitates expanding on classical physics. The pattern is seen only during Earth's alignments to two other heavenly bodies in our solar system lasting for more than three days. This empirical proof of astrophysical origins of seismotectonics is immediately obvious and verifiable. The find is consequential due to sheer size of processes and energies involved in defining the pattern that now enables all-or-nothing negative forecasting by foretelling dates without strong quakes. Earth's energy budget and tectonics are primarily astrophysical in origin, instead of geophysical as previously believed. Near coplanarity of a solar system's planets, which is for our solar system arguably regarded as odd, is in fact a necessary condition for active geophysics as a life system. The discovery has a potential for fundamentally rewriting physics, macrophysics in particular.

gravitation; cosmology; celestial mechanics; tides; patterns; tectonics; earthquakes; seismic forecasting

\section{Introduction}

Plate tectonics has shortcomings and it is not the ultimate Earth theory given problems it faces - ranging from scale, reference frame, dynamics and Earth evolution through time, to features or processes beyond plates; while some are related to idealization or approximation, other problems are more serious and unsolved, leading to substantial theoretical modifications. (Jacoby, 2001) It is not even understood why the Earth has plate tectonics (Stevenson, 2008).

However, in the situation of evident spatial correlation of seismicity and plate boundaries, precursory and other co-seismic qualities have been asserted or modeled for geophysical parameters and phenomena - ranging from event series (Tamrazyan, 1968) (Wyss, 1973), Gutenberg- Richter $b$-value (Fielder, 1974) (Smith, 1981) (Smith, 1986), to physical properties (Ihmlé, et al., 1994) (Ellsworth, et al., 2005) (Heki, 2011) (Heki, et al., 2015). While such assertions, along with claims of periods in earthquake time-series have been disputed, they still endure. For instance, lithosphere's tidal drag, famously posited by Alfred Wegener as the cause of continental drift, still draws attention (Crespi, et al., 2007).

A popular classical view maintains that heat transfer is responsible for global seismicity, volcanism and mountain building (Turcotte, et al., 2002). However, that view suffers from presumptiveness and laboratory confinement as essential data remain out of reach and mantle strain rate stays forbiddingly small for lab falsification. Also, near-surface thermal gradient estimates are coarse at best. It all makes the heat-transfer view provisional, convoluted and misleading. There is no obvious reason under that view why seismotectonics as a global phenomenon should belong in the same energy system with local phenomena such as volcanism and mountain building. Be it as a result of preference or out of need, but the heat transfer view amounts to a compilation of inexact theories (Menke, 1989) so that the main supplier of Earth's energy budget remains elusive and earthquake prediction futile.

Looking back, it is easy to state that it was not continental drift that failed, but the physical mechanism envisaged. Wegener clearly saw this and believed that, if observations demonstrate the kinematics, this is not invalidated by missing explanation or mechanism and driving forces ("the Newton for continental drift has not yet appeared"). (Jacoby, 2001)

\footnotetext{
${ }^{1}$ The Bosnian Royal Family, P.O. Box 1, Sarajevo Bosnia, hm@royalfamily.ba
} 


\section{Alternative... with opposite sign}

Here we report a universal physical principle governing seismotectonics of astronomical bodies from Space. The find is based on a pattern demonstrated empirically (by methodology and observation) for the Earth seismicity normally termed as strong: $\sim \mathrm{M}_{\mathrm{w}} 6+$ inclusive, where $\sim$ means $\pm 5 \%$. Though the pattern would resolve better if seisms were expressed in energy, depicting the pattern in magnitudes is also a physically valid but at the same time a more stringent approach for distinguishing (any) patterns empirically, i.e., while avoiding statistical analyses and testing as done here due to methodology that relies on non-normal distributions (Omerbashich, 2006) but provides highest accuracy (Baker, et al., 2015) (Omerbashich, 2015). Here the object of study is the entire Earth as related to the entire Solar system, so relying on methodology is the only option from physics point of view.

In search for a simpler yet all-embracing geophysics theory, extraterrestrial phenomena such as gravitation have been considered by many. Tidal drag under Earth rotation, arguably the strongest such primary (direct) tidal effect has been studied extensively due to preferential north-south orientation of plate boundaries. But the torque required by the magnitude of rotation turned out 10 orders of magnitude greater than tidal torques; in addition, the inferred asthenosphere viscosity would have to be that much lower from what is known (Jacoby, 2001).

Unlike direct tidal effects such as drag, which act as though impulsive, secondary tidal effects are cumulative and here include all other known and unknown gravitational effects either related or unrelated to Newtonian attraction directly. Due to the cumulativeness, there is no justification here for limiting our solar system's tidal effects to just the Sun's and the Moon's as done classically. Besides, our solar system exhibits numerous anomalies that reveal shortcomings of classical physics and could be or are a basis for new physics. (Iorio, 2015)

In the absence of terrestrial explanations for it, the N-S preferential orientation of tectonic plates is a strong indication of an extraterrestrial energizer of geophysics. Additionally, relative absence of seismicity in frigid zones narrows down possible locations of extraterrestrial seismogenic phenomena to force spaces perpendicular to Earth at lower latitudes or, more specifically, to our solar system's plane with inclination imagined at instantaneous-mean from planetary inclinations, except Pluto's for obvious reasons. Of all secondary tidal effects, that leaves us by elimination with the Earth oscillations magnification (due to our solar system's constellations in the said plane) as the only candidate for the main seismogenic mechanism and, inevitably, the all-inclusive geophysics theory as well.

In classical view masses attract masses via gravity. But at the same time, in a process usually taken to be trivial, gravity exerted by masses also stirs rotating masses from the core to the atmosphere. While that action inevitably causes masses to vibrate, it is important to note that seismic surface waves are just a limiting, high-frequency case of Earth free oscillations so the two are closely related (Menke, 1989). Then if a reverse physical connection could be demonstrated - between Earth's forced oscillations and strong earthquakes - that forcing would, as part of the connecting mechanism, reveal the physics behind those natural seisms.

The M6+ earthquakes account for around 2/3 of energy released by earthquakes. Then M6 is the natural (negligibly arbitrary) cutoff magnitude for faithfully representing the Earth while satisfying practical needs: optimal sample size and noise-to-signal ratio. Due to the above-mentioned and other shortcomings of current physics, no constraints can be placed on here applicable physics either. So we here consider the case of Earth forced oscillations with non-linear damping, where amplitude errors are of the order of a few per cent (Den Hartog, 1985). To avoid any critical surprises we cover that entire order, thus 
selecting the $\pm 5 \%$ window of comfort, throughout. As the window's upper limit, the M6.3 cutoff was then used here; notably, other related global studies used the same cutoff too (Suda, et al., 1998) but for the above practical needs alone.

Here an astronomical alignment is defined not by adhering to terminology, i.e., not simply as a geometric-instantaneous property of three point-masses in a coplanar solar system. Instead, an alignment is defined to be a kinematic property as viewed on a common astronomical chart of a common resolution, and is said to start at -1 day from the date on which the absolute differential angular velocity $d \omega$ of the alignment's two possible lines of sight (Earth-Body $\left.)_{1}\right),\left(\right.$ Earth-Body $y_{2}$ falls below minimum time-resolution, i.e., $\left|d \omega_{i}\right|<1$ day: $\mathrm{i}=-\infty \ldots-1$. This expression has infinitely many solutions but suffices thanks to apparent slowness of our everyday timescale. So for each observed arc that the Earth (strictly: its projection) traces in (on) the solar system's plane we can safely discard all but precisely one solution - that within 5\% in time and (projection) space from the alignment of interest. And just as virtually non-existent inclinations of our solar system's bodies make that system here regarded a plane, the Earth's projection onto that plane becomes a nonissue also. All dated features of this research are precise to \pm 1 day. Most of digital astronomical charts nowadays suffice for finding alignments in the above manner, so the chart choice is trivial.

\section{Pattern}

Figure 1 reveals an obvious pattern, of first strengthening, then peaking, and then finally waning Earth's strong seismicity during astronomical alignments to two other heavenly bodies longer than 3 days. The pattern occurs mostly at the alignment's onset, reaching excitement levels beyond M7 during most weeks-long alignments as well as in most cases of two simultaneous alignments longer than 3 days. The system's constellations were simple in the sense of relatively infrequent simultaneous alignments, Figure 2, but the pattern is formed under more intricate constellations as well, and is also found in historic records of earthquakes (Omerbashich, 2011). A randomly chosen alignment, of 1 decade ago, reveals the same pattern, Figure 3. The pattern gets better resolved with increase in M6.3+ earthquakes, Figure 4. Surprisingly, the pattern-alignment correlation is immediately discernible to all audiences, so physics alone vindicates the above-stated inadequacy to perform statistical analyses and tests; a phenomenon supplying 2/3 of Earth energy budget requires no statistics.

In deciphering the physical meaning of the discovered pattern we are faced with a couple of dilemmas that luckily can be decided on by simple elimination. One dilemma is trivial and concerns the question of whether, at the present geological time, the strong seismicity is affecting our solar system's constellations, or if it is the constellations that are affecting the strong seismicity. The other dilemma is more complex, and asks whether the constellations are affecting strong seismicity but not tectonics, or in fact both simultaneously. In the former case however, it would be the only real rival to extraterrestrial view - namely the thermal transfer view - which would have to be responsible for the entire tectonics but none of strong seismicity. However, such arbitrary differentiation is physically implausible if not forbidden under that view, given the mentioned obvious spatial correlation between strong seismicity and plate boundaries, and for other reasons.

Therefore, one is led by elimination alone to conclude that only the extraplanetary view reveals the mechanism for overall seismotectonics as a phenomenon. For example, while the thermal transfer view cannot conclusively explain deep seisms since those occur in nonbrittle environments, in the extraterrestrial view they are parts of the same mechanism and do participate in an unbiased manner together in forming the pattern; Table 1. 
(a)

10 Oct 11 Oct 14 Oct

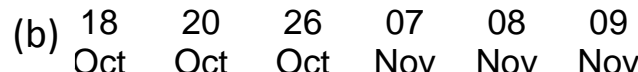

(c) $\begin{array}{llll}09 & 11 & 13 & 17\end{array}$

Nov Nov Nov Nov
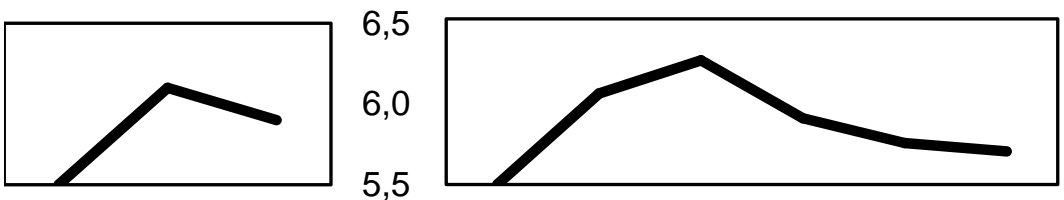

Saturn - Earth - Uranus

Jupiter - Venus - Earth

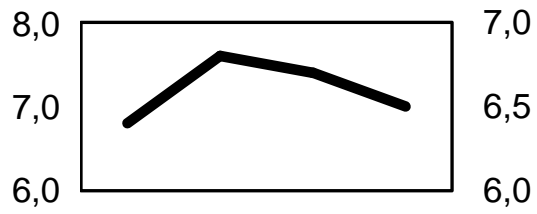

$\begin{array}{llllllll}\text { (d) } & 17 & 18 & 24 & 26 & 27 & 28 & 29\end{array}$ Nov Nov Nov Nov Nov Nov Nov

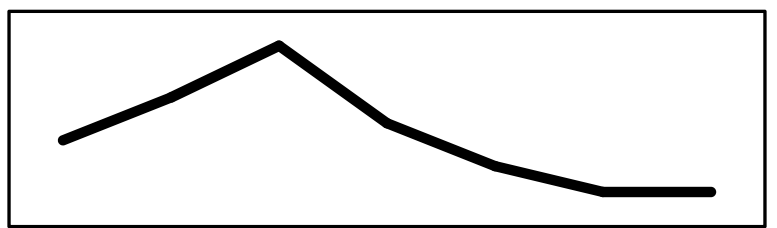

Venus - Earth - Uranus

(f)

$1 \mathrm{Dec} 4 \mathrm{Dec} 7 \mathrm{Dec} 9 \mathrm{Dec} 9 \mathrm{Dec} 10 \mathrm{Dec}$

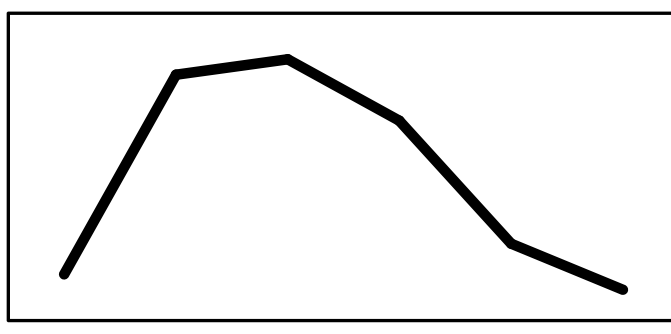

Earth - Sun - Saturn

(h) 31 Dec 1 Jan 3 Jan 11 Jan 11 Jan 12 Jan

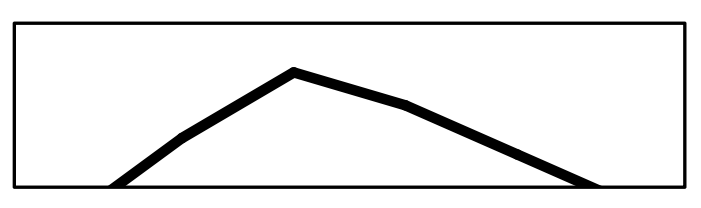

7,0

6,5

6,0

Saturn - Venus - Earth

(j) 21 Jan 24 Jan 25 Jan 26 Jan

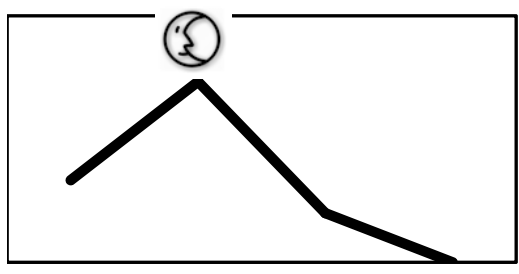

Full Moon (Sun-Earth-Moon)

(e)

$\begin{array}{ccccc}10 & 17 & 19 & 20 & 23 \\ \text { Dec } & \text { Dec } & \text { Dec } & \text { Dec } & \text { Dec }\end{array}$

7,5
6,5
5,5

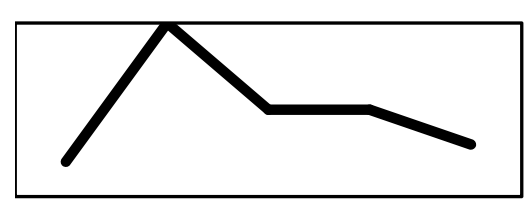

Mars - Earth - Uranus

(g)

$23 \mathrm{Dec} 24 \mathrm{Dec} 25 \mathrm{Dec} 28 \mathrm{Dec}$

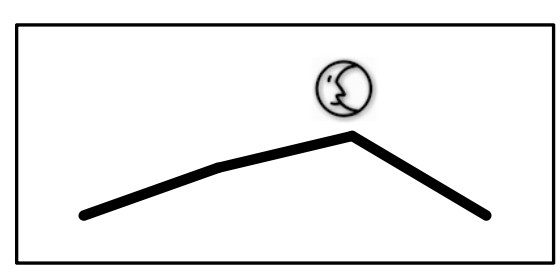

7,0

6,5

Full Moon (Sun-Earth-Moon)

(i) 14 Jan 14 Jan 21 Jan

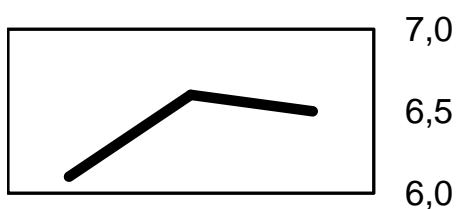

Earth - Mercury - Sun

(k) 27 Jan 30 Jan 05 Feb 08 Feb 10 Feb 12 Feb

7,5
7,0
6,5
6,0

6,0

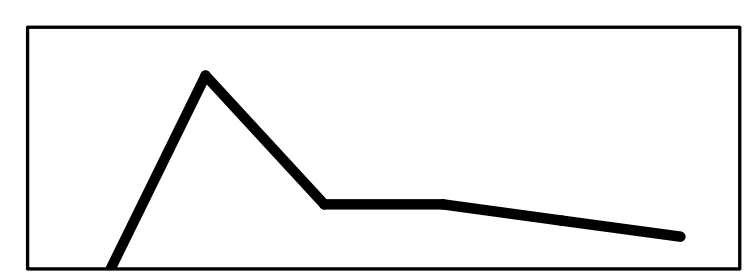

7,5

7,0

6,5

6,0

Figure 1. The 28, M6.3+ earthquakes, Table 1, forming an increase-peak-decrease pattern always and only during astronomical alignments longer than 3 days, see Figure 2. The M5.7-M6.2 quakes are useful as magnification's trending/jolting indicators, and pattern enhancers (at ends only) to stress that patterns depict Earth's excited state. The M6.3+ mostly occur at alignment onset, adding a forecasting quality. Shown are all 11 alignments a-k, Figure 2. 
The observed phenomenon Figure 1 obviously resembles excitations in a mechanical oscillator; this also based on the observation that M5.7-M6.2 seismicity is seen as preceding and following the pattern; and when co-occurring with the pattern, this $M(6 \pm 5 \%)$ seismicity resembles oscillator's jolting episodes arising as sheathing instability at the oscillator's periphery, and corresponds largely to deep seisms; see Table 1. That a true oscillator is at work is also seen from the fact that 3 or more simultaneous alignments of the Earth with different pairs of heavenly bodies result in no M6.3+ excitation - as expected from overexcited damping in a weakly insulated oscillator exposed to both forced and internal interference; here tacitly presumed to be the case with the Earth shielded in crusty lithosphere. Thus under the extraterrestrial view, in which case the oscillator's periphery is not bounded by just the lithosphere, primarily deep seismicity is the Earth's normal seismicity.

Indeed, equations of a forced mechanical oscillator with viscous damping (Den Hartog, 1985), as the limiting case, result for Earth's usual parameters and mantle viscosity in 3days mantle response-phase and the well-known maximum co-seismic displacement of around $10 \mathrm{~m}$; remarkably, 3-day phase is also obtained as a precursory cross-correlation of decadal deep (conventionally: below $400 \mathrm{~km}$ ) M6.3+ earthquakes with spectra of (the spectra of) Earth mass accelerations from corresponding decadal $1 \mathrm{~Hz}$ records by superconducting gravimeters that normally serve as broadband seismometers too; the phase is shorter in the case of shallow seisms, and takes up to several hours to initiate (Omerbashich, 2007). This justifies the concept of the Earth as an oscillation magnifier.

From the vibrational mechanics point of view, only bodies with their own mantle acting as a combustion chamber, and their own crust acting as a rather poor casing, can be considered insufficiently insulated and thus prone to significant forced seismotectonics. This in turn acts as a balancing factor for keeping the oscillator flexible enough in order to prevent it from busting and/or dispersing. In the same view then, volcanoes and tectonics act like vents and gadgets for keeping the Earth oscillator mechanically and otherwise stable. It seems natural to note at this point that magnetism and electricity naturally arise in a mechanical oscillator (Den Hartog, 1985).

That a new physics is indeed possible based on the above concept of the Earth as a forced mechanical oscillator and natural magnifier of vibration, can be shown by generalizing the concept to all scales and energies (Omerbashich, 2012). That approach results in intriguing absolute scaling relationships closed amongst (values of) the Newtonian gravitational constant G (and thus gravity itself) at both classical and quantum scales, and the speed of light, as hinted by Einstein in his treatise on geophysics (Schröder, et al., 1997). That approach also makes the first successful theoretical prediction of G, in this case as obtained experimentally by BIPM (Omerbashich, 2015), as well as analytically relates the BIPM and NIST values of G. 


\begin{tabular}{|c|c|c|c|c|c|}
\hline M5.6+ Earthquake (date, GMT, focal depth, lat, long, location) & trend & $\mathrm{M}_{\mathrm{w}}$ & USGS & EMSC & GFZ \\
\hline $14 \mathrm{Feb} 2016,18: 09: 26|418 \mathrm{~km}| 30.3^{\circ} \mathrm{N}, 138.8^{\circ} \mathrm{E} \mid \mathrm{SE}$ of Honshu, JP & $\boldsymbol{\nabla}$ & 5.7 & 5.7 & 5.5 & 5.7 \\
\hline $14 \mathrm{Feb} 2016,00: 13: 43|10 \mathrm{~km}| 43.4^{\circ} \mathrm{S}, 172.8^{\circ} \mathrm{E} \mid$ New Zealand & $\boldsymbol{\nabla}$ & 5.8 & 5.8 & 5.8 & 5.7 \\
\hline \begin{tabular}{ll|l|l|l|}
$2 \mathrm{Feb} 2016,10: 02: 24$ & $33 \mathrm{~km}$ & $9.8^{\circ} \mathrm{S}, 119.4^{\circ} \mathrm{E}$ & Sumba, Indonesia \\
\end{tabular} & $\boldsymbol{\nabla}$ & 6.2 & 6.3 & 6.2 & 6.2 \\
\hline 10 Feb 2016, 00:33:05 $|30 \mathrm{~km}| 30^{\circ}{ }^{\circ} \mathrm{S},{71.6^{\circ} \mathrm{W}}^{\prime}$ Papua New Guinea & $\boldsymbol{\nabla}$ & 6.3 & 6.3 & 6.3 & 6.3 \\
\hline 08 Feb 2016, 16:19:15 $|41 \mathrm{~km}| 6.6^{\circ} \mathrm{S}, 154.7^{\circ} \mathrm{E} \mid$ Papua New Guinea & & 6.4 & 6.4 & 6.5 & 6.4 \\
\hline \begin{tabular}{ll|l|l|l}
$\mathrm{Feb} 2016,02: 03: 35$ & $10 \mathrm{~km}\left|15.2^{\circ} \mathrm{S}, 173.5^{\circ} \mathrm{W}\right|$ Tonga Isles \\
\end{tabular} & $\boldsymbol{\nabla}$ & 5.8 & 5.8 & 5.8 & 5.8 \\
\hline 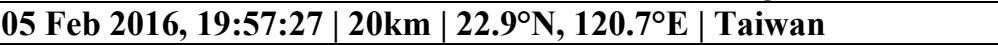 & & 6.4 & 6.4 & 6.4 & 6.3 \\
\hline $02 \mathrm{Feb} 2016,14: 19: 22|191 \mathrm{~km}| 25.6^{\circ} \mathrm{N}, 123.5^{\circ} \mathrm{E} \mid \mathrm{NE}$ of Taiwan & $\boldsymbol{\nabla}$ & 5.7 & 5.7 & 5.7 & 5.6 \\
\hline $01 \mathrm{Feb} 2016,19: 00: 45|382 \mathrm{~km}| 30.9^{\circ} \mathrm{S}, 180.0^{\circ} \mathrm{E} \mid$ New Zealand & & 6.2 & 6.2 & 6.2 & 6.2 \\
\hline 31 Jan $2016,17: 39: 01|10 \mathrm{~km}| 63.3^{\circ} \mathrm{S}, 169.6^{\circ} \mathrm{E} \mid$ Balleny isles region & $\boldsymbol{\nabla}$ & 6.0 & 6.0 & 6.0 & 6.0 \\
\hline 30 Jan 2016, 03:25:10 $|161 \mathrm{~km}| 54.0^{\circ} \mathrm{N}, 158.5^{\circ} \mathrm{E} \mid$ Kamchatka, RU & & 7.2 & 7.2 & 7.2 & 7.2 \\
\hline 27 Jan $2016,15: 11: 19|10 \mathrm{~km}| 1.0^{\circ} \mathrm{N}, 28.2^{\circ} \mathrm{W} \mid$ Ce.Mid-Atlantic Ridge & $\mathbf{\Delta}$ & 5.7 & 5.7 & 5.6 & 5.7 \\
\hline 26 Jan $2016,03: 10: 23|44 \mathrm{~km}| 5.3^{\circ} \mathrm{S}, 153.2^{\circ} \mathrm{E} \mid$ Papua New Guinea & $\boldsymbol{\nabla}$ & 6.0 & 5.8 & 6.0 & 6.1 \\
\hline 25 Jan 2016, 04:22:02 $|10 \mathrm{~km}| 35.7^{\circ} \mathrm{N}, 3.7^{\circ} \mathrm{W} \mid$ Morocco-Gibraltar & & 6.3 & 6.3 & 6.3 & 6.3 \\
\hline 25 Jan $2016,00: 00: 10|40 \mathrm{~km}| 19.4^{\circ} \mathrm{S}, 173.5^{\circ} \mathrm{W} \mid$ Tonga isles & $\boldsymbol{\nabla}$ & 5.7 & 5.7 & 5.7 & 5.6 \\
\hline 24 Jan 2016, 10:30:30 $|128 \mathrm{~km}| 59.7^{\circ} \mathrm{N}, 153.5^{\circ} \mathrm{W} \mid$ southern Alaska & & 7.1 & 7.1 & 7.1 & 7.1 \\
\hline 21 Jan 2016, 18:06:58 $|10 \mathrm{~km}| 18.8^{\circ} \mathrm{N}, 107.0^{\circ} \mathrm{W} \mid$ off coast Mexico & & 6.5 & 6.6 & 6.5 & 6.5 \\
\hline 20 Jan $2016,17: 13: 14|10 \mathrm{~km}| 37.7^{\circ} \mathrm{N}, 101.6^{\circ} \mathrm{E} \mid$ Qinghai, China & $\Delta$ & 5.9 & 5.9 & 5.9 & 5.9 \\
\hline 18 Jan $2016,18: 24: 26|24 \mathrm{~km}| 21.5^{\circ} \mathrm{S}, 175.9^{\circ} \mathrm{E} \mid$ south of Fiji isles & $\boldsymbol{\Delta}$ & 5.9 & 5.8 & 5.9 & 6.0 \\
\hline 14 Jan $2016,11: 04: 22|30 \mathrm{~km}| 15.6^{\circ} \mathrm{S}, 177.3^{\circ} \mathrm{W} \mid$ Fiji isles region & $\boldsymbol{\nabla}$ & 5.7 & 5.6 & 5.7 & 5.7 \\
\hline 14 Jan 2016, 03:25:34 $|51 \mathrm{~km}| 42.0^{\circ} \mathrm{N}, 142.7^{\circ} \mathrm{E} \mid$ Hokkaido, Japan & & 6.6 & 6.7 & 6.6 & 6.6 \\
\hline 14 Jan 2016, 03:25:27 | 579km | $19.8^{\circ} \mathrm{S}, 63.3^{\circ} \mathrm{W} \mid$ Santa Cruz, Bolivia & $\mathbf{\Delta}$ & 6.1 & 6.1 & 6.1 & 6.0 \\
\hline 13 Jan $2016,05: 56: 01|257 \mathrm{~km}| 15.2^{\circ} \mathrm{S}, 174.9^{\circ} \mathrm{W} \mid$ Tonga isles & $\Delta$ & 5.8 & 5.8 & 5.8 & 5.9 \\
\hline 12 Jan 2016, 20:05:00 $|242 \mathrm{~km}| 36.6^{\circ} \mathrm{N}, 71.1^{\circ} \mathrm{E} \mid$ Afghan.-Tajikistan & $\boldsymbol{\nabla}$ & 5.7 & 5.7 & 5.7 & 5.7 \\
\hline 12 Jan $2016,09: 45: 11|10 \mathrm{~km}| 31.5^{\circ} \mathrm{S}, 58.2^{\circ} \mathrm{E} \mid \mathrm{S}-\mathrm{W}$ Indian Ridge & $\boldsymbol{\nabla}$ & 5.9 & 5.9 & 5.9 & 5.9 \\
\hline 11 Jan $2016,17: 08: 03|228 \mathrm{~km}| 44.5^{\circ} \mathrm{N}, 141.1^{\circ} \mathrm{E} \mid$ Japan & $\boldsymbol{\nabla}$ & 6.2 & 6.2 & 6.1 & 6.2 \\
\hline 11 Jan 2016, 16:38:06 $|10 \mathrm{~km}| 3.9^{\circ} \mathrm{N},{126.9^{\circ} \mathrm{E}}_{\mid}$Indonesia seas & & 6.5 & 6.5 & 6.5 & 6.5 \\
\hline $10 \mathrm{Jan} 2016,12: 12: 03|10 \mathrm{~km}| 57.7^{\circ} \mathrm{S}, 147.9^{\circ} \mathrm{W} \mid$ PacificAntarct.Ridge & $\mathbf{\Delta}$ & 5.7 & 5.6 & 5.7 & 5.7 \\
\hline 08 Jan $2016,01: 12: 01|31 \mathrm{~km}| 30.7^{\circ} \mathrm{S}, 71.7^{\circ} \mathrm{W} \mid$ Chile & $\Delta$ & 5.6 & 5.6 & 5.6 & 5.7 \\
\hline \begin{tabular}{ll|l}
$05 \mathrm{Jan} 2016,21: 59: 50$ & $157 \mathrm{~km}\left|22.0^{\circ} \mathrm{N}, 143.7^{\circ} \mathrm{E}\right|$ Marianas region \\
\end{tabular} & $\boldsymbol{\nabla}$ & 5.7 & 5.9 & 5.7 & 5.6 \\
\hline 05 Jan $2016,09: 34: 15|10 \mathrm{~km}| 54.3^{\circ} \mathrm{S}, 136.2^{\circ} \mathrm{W} \mid$ Pacif-Antarct. Ridge & $\Delta$ & 6.0 & 6.0 & 5.9 & 6.0 \\
\hline 05 Jan $2016,02: 21: 13|10 \mathrm{~km}| 30.6^{\circ} \mathrm{N}, 132.8^{\circ} \mathrm{E} \mid$ off Shikoku, Japan & $\boldsymbol{\nabla}$ & 5.9 & 5.8 & 5.9 & 5.9 \\
\hline 03 Jan 2016, 23:05:20 | 39km $\mid 24.8^{\circ} \mathrm{N},{93.6^{\circ} \mathrm{E}}^{0}$ Manipur, India & & 6.7 & 6.7 & 6.7 & 6.7 \\
\hline 02 Jan $2016,04: 22: 19|585 \mathrm{~km}| 44.8^{\circ} \mathrm{N}, 130.0^{\circ} \mathrm{E} \mid$ Chaihe, China & $\mathbf{\Delta}$ & 5.8 & 5.7 & 5.8 & 5.8 \\
\hline 01 Jan 2016, 15:02:15 $|37 \mathrm{~km}| 29.1^{\circ} \mathrm{S}, 177.1^{\circ} \mathrm{W} \mid$ New Zealand & $\boldsymbol{\nabla}$ & 5.8 & 5.8 & 5.8 & 5.5 \\
\hline 01 Jan 2016, 02:00:40 $|10 \mathrm{~km}| 50.6^{\circ} \mathrm{S}, 139.4^{\circ} \mathrm{E} \mid$ W. Ind.-Ant. Ridge & & 6.3 & 6.3 & 6.3 & 6.3 \\
\hline 31 Dec $2015,10: 57: 00|37 \mathrm{~km}| 11.2^{\circ} \mathrm{N}, 86.6^{\circ} \mathrm{W} \mid$ off coast Nicaragua & $\Delta$ & 5.8 & 5.7 & 5.8 & 5.8 \\
\hline 29 Dec $2015,01: 51: 44|55 \mathrm{~km}| 6.3^{\circ} \mathrm{S}, 154.7^{\circ} \mathrm{E} \mid$ Papua New Guinea & $\boldsymbol{\nabla}$ & 5.8 & 5.8 & 5.8 & 5.7 \\
\hline 25 Dec 2015, 19:14:47 $|203 \mathrm{~km}| 36.5^{\circ} \mathrm{N}, 7^{21.2^{\circ} \mathrm{E}} \mid$ Afgh.-Tajikistan & & 6.3 & 6.3 & 6.2 & 6.3 \\
\hline 25 Dec $2015,17: 58: 05|10 \mathrm{~km}| 40.7^{\circ} \mathrm{S}, 86.5^{\circ} \mathrm{W} \mid$ West Chile Rise & $\mathbf{\Delta}$ & 5.7 & 5.7 & 5.7 & 5.7 \\
\hline \begin{tabular}{ll|l|l|l}
$24 \operatorname{Dec} 2015,23: 10: 58$ & $127 \mathrm{~km}\left|7.3^{\circ} \mathrm{S}, 129.1^{\circ} \mathrm{E}\right|$ Banda Sea Indonesia \\
\end{tabular} & $\boldsymbol{\nabla}$ & 5.8 & 5.8 & 5.8 & 5.7 \\
\hline $24 \operatorname{Dec} 2015,19: 44: 03|10 \mathrm{~km}| 55.8^{\circ} \mathrm{S}, 123.1^{\circ} \mathrm{W} \mid \mathrm{S}$. East Pacific Rise & & 6.1 & 6.1 & 6.1 & 6.2 \\
\hline 23 Dec $2015,16: 55: 10|15 \mathrm{~km}| 54.2^{\circ} \mathrm{S}, 1.5^{\circ} \mathrm{W} \mid$ Bouvet Antarctica NO & $\Delta \boldsymbol{\nabla}$ & 5.8 & 5.8 & 5.8 & 5.8 \\
\hline 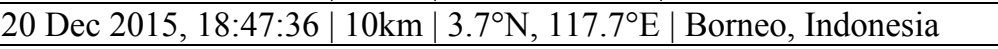 & & 6.0 & 6.0 & 6.1 & 6.0 \\
\hline $19 \operatorname{Dec} 2015,19: 25: 04|48 \mathrm{~km}| 30.6^{\circ} \mathrm{S}, 71.2^{\circ} \mathrm{W} \mid$ off coast, Chile & $\mathbf{\Delta} \boldsymbol{\nabla}$ & 5.8 & 5.8 & 5.8 & 5.8 \\
\hline 19 Dec $2015,02: 10: 54|10 \mathrm{~km}| 18.2^{\circ} \mathrm{S}, 169.4^{\circ} \mathrm{E} \mid$ Vanuatu isles & $\boldsymbol{\nabla}$ & 6.0 & 6.0 & 6.0 & 6.0 \\
\hline 17 Dec 2015, 19:49:54 $|94 \mathrm{~km}| 15.9^{\circ} \mathrm{N}, 93.4^{\circ} \mathrm{W} \mid$ Chiapas, Mexico & & 6.5 & 6.6 & 6.5 & 6.5 \\
\hline 10 Dec $2015,12: 05: 15|10 \mathrm{~km}| 59.0^{\circ} \mathrm{S}, 24.0^{\circ} \mathrm{W} \mid$ South Sandwich Isles & $\nabla \mathbf{B}$ & 5.7 & 5.7 & 5.7 & 5.8 \\
\hline 09 Dec $2015,12: 58: 01|10 \mathrm{~km}| 16.7^{\circ} \mathrm{S}, 175.3^{\circ} \mathrm{E} \mid$ Fiji Isles region & $\boldsymbol{\nabla}$ & 6.0 & 6.1 & 6.0 & 6.0 \\
\hline 09 Dec 2015, 10:21:51 $|45 \mathrm{~km}| 4.1^{\circ} \mathrm{S}, 129.5^{\circ} \mathrm{E} \mid$ BandaSeaIndonesia & $\boldsymbol{\nabla}$ & 6.8 & 6.9 & 6.8 & 6.8 \\
\hline 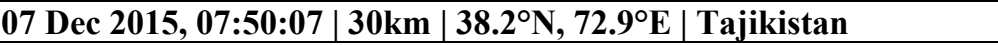 & & 7.2 & 7.2 & 7.2 & 7.2 \\
\hline 04 Dec 2015, 22:24:54 $|10 \mathrm{~km}| 47.7^{\circ} \mathrm{S}, 85.2^{\circ} \mathrm{E} \mid$ S-E Indian Ridge & $\boldsymbol{\Delta}$ & 7.1 & 7.1 & 7.1 & 7.0 \\
\hline \begin{tabular}{|l|l|l|}
01 Dec $2015,17: 08: 26$ & $10 \mathrm{~km} \mid$ & $15.0^{\circ} \mathrm{S}, 176.6^{\circ} \mathrm{W} \mid$ Fiji Isles region \\
\end{tabular} & $\boldsymbol{\nabla} \boldsymbol{\Delta}$ & 5.8 & 5.8 & 5.8 & 5.7 \\
\hline
\end{tabular}




\begin{tabular}{|c|c|c|c|c|c|c|}
\hline 29 Nov $2015,18: 52: 50$ & $10 \mathrm{~km}\left|23.6^{\circ} \mathrm{S}, 64.6^{\circ} \mathrm{W}\right|$ Argentina & $\boldsymbol{\nabla}$ & 5.9 & 5.9 & 5.9 & 5.7 \\
\hline 28 Nov $2015,02: 51: 07$ & 711km $\left|43.3^{\circ} \mathrm{N}, 146.5^{\circ} \mathrm{E}\right|$ Kuril Isles, Russia & $\boldsymbol{\nabla}$ & 5.9 & 5.6 & 5.9 & 5.8 \\
\hline 27 Nov 2015, 21:00:22 & $|30 \mathrm{~km}| 24.8^{\circ} \mathrm{S}, 70.6^{\circ} \mathrm{W} \mid$ offshore N. Chile & $\boldsymbol{\nabla}$ & 6.2 & 6.2 & 6.2 & 6.1 \\
\hline 26 Nov 2015, 05:45:18 & $|601 \mathrm{~km}| 9.2^{\circ} \mathrm{S}, 71.3^{\circ} \mathrm{W} \mid$ Peru-Brazil border & $\boldsymbol{\nabla}$ & 6.7 & 6.7 & 6.7 & 6.7 \\
\hline 24 Nov 2015, 22:50:54 & $|613 \mathrm{~km}| 10.0^{\circ} \mathrm{S}, 71.0^{\circ} \mathrm{W} \mid$ Peru-Brazil bord. & & 7.6 & 7.6 & 7.6 & 7.6 \\
\hline 24 Nov $2015,13: 21: 36$ & \begin{tabular}{|l|l|l|l|l}
$590 \mathrm{~km}$ & $18.8^{\circ} \mathrm{N}, 145.3^{\circ} \mathrm{E} \mid$ Mariana Isles \\
\end{tabular} & $\mathbf{\Delta}$ & 6.0 & 6.0 & 6.0 & 6.0 \\
\hline 22 Nov $2015,18: 16: 05$ & 92km $\left|36.5^{\circ} \mathrm{N}, 71.6^{\circ} \mathrm{E}\right|$ Afgh.-Tajikistan & $\boldsymbol{\nabla}$ & 5.7 & 5.7 & 5.8 & 5.7 \\
\hline 21 Nov 2015, 09:06:14 & $97 \mathrm{~km}\left|7.3^{\circ} \mathrm{S}, 130.0^{\circ} \mathrm{E}\right|$ Tanimbar, Indonesia & $\boldsymbol{\nabla}$ & 6.1 & 6.1 & 6.1 & 6.0 \\
\hline 18 Nov 2015, 18:31:04 & $|10 \mathrm{~km}| 9^{9.0^{\circ}} \mathrm{S}, 158.4^{\circ} \mathrm{E} \mid$ Solomon Isles & & 7.0 & 7.0 & 7.0 & 6.8 \\
\hline 17 Nov 2015, 07:10:09 & $|10 \mathrm{~km}| 38.8^{\circ} \mathrm{N}, 20.5^{\circ} \mathrm{E} \mid$ off Nidri, Greece & $\mathbf{\Delta}$ & 6.5 & 6.5 & 6.5 & 6.4 \\
\hline 16 Nov $2015,16: 49: 15$ & $|40 \mathrm{~km}| 48.3^{\circ} \mathrm{N}, 154.3^{\circ} \mathrm{E} \mid$ Kuril Isles, Russia & $\boldsymbol{\Delta}$ & 5.9 & 5.9 & 5.9 & 5.9 \\
\hline 16 Nov $2015,00: 39: 33$ & $10 \mathrm{~km}\left|17.8^{\circ} \mathrm{N}, 81.9^{\circ} \mathrm{W}\right|$ Cayman Isles region & $\boldsymbol{\Delta}$ & 5.8 & 5.8 & 5.8 & 5.7 \\
\hline 14 Nov $2015,19: 20: 21$ & $10 \mathrm{~km}\left|31.4^{\circ} \mathrm{N}, 128.8^{\circ} \mathrm{E}\right|$ off Kyushu, Japan & $\boldsymbol{\nabla}$ & 5.7 & 5.7 & 5.7 & 5.7 \\
\hline 13 Nov 2015, 20:51:37 & $|10 \mathrm{~km}| 31.0^{\circ} \mathrm{N}, 128.8^{\circ} \mathrm{E} \mid$ off Ryukyu Japan & & 6.7 & 6.7 & 6.7 & 6.7 \\
\hline 11 Nov 2015, 23:36:19 & $140 \mathrm{~km}\left|7.3^{\circ} \mathrm{S}, 129.0^{\circ} \mathrm{E}\right|$ Banda Sea Indonesia & $\boldsymbol{\nabla} \boldsymbol{\Delta}$ & 5.8 & 5.7 & 5.8 & 5.8 \\
\hline 11 Nov 2015, 01:54:38 & $|10 \mathrm{~km}| 29.4^{\circ} \mathrm{S}, 71.9^{\circ} \mathrm{W} \mid$ off coast, cen.Chile & & 6.8 & 6.9 & 6.8 & 6.8 \\
\hline 09 Nov 2015, 16:03:45 & $|10 \mathrm{~km}| 51.7^{\circ} \mathrm{N}, 173.0^{\circ} \mathrm{W} \mid$ Aleutians, Alaska & $\boldsymbol{\nabla} \boldsymbol{A}$ & 6.4 & 6.5 & 6.4 & 6.4 \\
\hline 08 Nov 2015, 16:47:01 & $|10 \mathrm{~km}| 6.8^{\circ} \mathrm{N}, 94.6^{\circ} \mathrm{E} \mid$ Nicobar Isles, India & & 6.5 & 6.6 & 6.5 & 6.5 \\
\hline 08 Nov $2015,09: 34: 58$ & 80km | $0.7^{\circ} \mathrm{N}, 98.9^{\circ} \mathrm{E} \mid$ Sumatra, Indonesia & $\boldsymbol{\Delta}$ & 5.7 & 5.7 & 5.8 & 5.7 \\
\hline 07 Nov $2015,10: 53: 43$ & $153 \mathrm{~km}\left|30.8^{\circ} \mathrm{S}, 71.4^{\circ} \mathrm{W}\right|$ off coast Chile & $\boldsymbol{\nabla}$ & 5.7 & 5.7 & 5.7 & 5.7 \\
\hline 07 Nov 2015, 07:31:43 & $|40 \mathrm{~km}| 30.9^{\circ} \mathrm{S}, 71.5^{\circ} \mathrm{W} \mid$ off coast $C h i l e$ & & 6.8 & 6.8 & 6.9 & 6.7 \\
\hline 04 Nov 2015, 03:44:15 & $|15 \mathrm{~km}| 8.3^{\circ} \mathrm{S}, 124.9^{\circ} \mathrm{E} \mid$ Timor; Indonesia & $\boldsymbol{\Delta}$ & 6.5 & 6.5 & 6.5 & 6.5 \\
\hline 02 Nov 2015, 08:15:34 & | $20 \mathrm{~km}\left|51.7^{\circ} \mathrm{N}, 173.4^{\circ} \mathrm{W}\right|$ Alaska, USA & $\boldsymbol{\Delta}$ & 5.9 & 5.8 & 5.8 & 5.7 \\
\hline 01 Nov $2015,15: 16: 16$ & $|105 \mathrm{~km}| 23.3^{\circ} \mathrm{S}, 68.3^{\circ} \mathrm{W} \mid$ Antofagasta, Chile & $\Delta$ & 5.9 & 5.9 & 5.9 & 5.9 \\
\hline 28 Oct $2015,20: 46: 41$ & $153 \mathrm{~km}\left|11.0^{\circ} \mathrm{S}, 166.4^{\circ} \mathrm{E}\right|$ Santa Cruz Isles & $\boldsymbol{\nabla}$ & 5.8 & 5.8 & 5.8 & 5.7 \\
\hline 26 Oct 2015, 09:09:32 & $|212 \mathrm{~km}| 36.4^{\circ} \mathrm{N},{70.9^{\circ} \mathrm{E}}^{\mid}$Afghanistan & & 7.5 & 7.5 & 7.5 & 7.5 \\
\hline 25 Oct $2015,14: 58: 57$ & $10 \mathrm{~km}\left|29.3^{\circ} \mathrm{S}, 177.8^{\circ} \mathrm{E}\right|$ New Zealand & $\boldsymbol{\Delta}$ & 5.7 & 5.7 & 5.7 & 5.7 \\
\hline 23 Oct $2015,22: 03: 23$ & $10 \mathrm{~km}\left|2.1^{\circ} \mathrm{S}, 138.2^{\circ} \mathrm{E}\right|$ Papua, Indonesia & $\boldsymbol{\nabla}$ & 5.7 & 5.7 & 5.7 & 5.6 \\
\hline 23 Oct $2015,04: 04: 18$ & $10 \mathrm{~km}\left|45.8^{\circ} \mathrm{S}, 37.1^{\circ} \mathrm{E}\right|$ Prince Edw.Isles, SAR & $\boldsymbol{\nabla}$ & 6.0 & 6.0 & 6.0 & 6.0 \\
\hline 23 Oct $2015,01: 40: 06$ & $10 \mathrm{~km}\left|54.3^{\circ} \mathrm{S}, 6.1^{\circ} \mathrm{E}\right|$ Bouvet Isle, Norway & $\boldsymbol{\nabla}$ & 6.1 & 6.2 & 6.1 & 6.1 \\
\hline 20 Oct 2015, 21:52:03 & $|145 \mathrm{~km}| 14.9^{\circ} \mathrm{S}, 167.3^{\circ} \mathrm{W} \mid$ Vanuatu & & 7.1 & 7.1 & 7.1 & 7.0 \\
\hline 18 Oct $2015,16: 18: 35$ & \begin{tabular}{l|l}
$10 \mathrm{~km}$ & $16.1^{\circ} \mathrm{S}, 173.4^{\circ} \mathrm{W} \mid$ Tonga islands \\
\end{tabular} & $\boldsymbol{\Delta}$ & 6.0 & 6.0 & 6.0 & 6.0 \\
\hline 17 Oct $2015,11: 33: 09$ & $18 \mathrm{~km}\left|25.4^{\circ} \mathrm{S}, 64.6^{\circ} \mathrm{W}\right|$ Salta, Argentina & $\bar{\Delta}$ & 5.8 & 5.8 & 5.9 & 5.7 \\
\hline 14 Oct $2015,05: 43: 08$ & $10 \mathrm{~km}\left|48.8^{\circ} \mathrm{N}, 156.2^{\circ} \mathrm{E}\right|$ Kuril Isles, Russia & $\boldsymbol{\nabla}$ & 6.0 & 6.0 & 5.9 & 6.0 \\
\hline 11 Oct $2015,00: 58: 27 \mid$ & $10 \mathrm{~km}\left|54.5^{\circ} \mathrm{S}, 135.8^{\circ} \mathrm{W}\right|$ Pacif.Antarct. Ridge & & 6.1 & 5.5 & 6.1 & 6.1 \\
\hline 10 Oct $2015,08: 56: 06$ & $10 \mathrm{~km}\left|60.7^{\circ} \mathrm{S}, 20.8^{\circ} \mathrm{W}\right|$ South Sandwich Isles & $\mathbf{\Delta}$ & 5.5 & 5.5 & 5.5 & 5.5 \\
\hline
\end{tabular}

Table 1: Used were all M5.6+ quakes from the October 2015-March 2016 test-interval, from USGS, EMSC and GFZ as the three arguably most reliable sources. Used was the $\mathrm{M}_{\mathrm{w}}$ mean value, after discarding outliers and magnitudes of other types that would affect the mean by more than \pm 0.1 . The peak-magnitude in each distinct M5.6+ episode/jolt is marked by omitting of trending arrows. The 28, M6.3+ earthquakes, marked bold, are seen on Figure 1 as forming a distinct increase-peakingdecrease pattern. Data are restricted to the shown span because astronomical data, which supposedly control geophysical data, are naturally repetitive, so half-a-year seemed a reasonable span for mimicking the repetitiveness in the presumed astral relationship. That this assumption was correct is seen from Figs. 3 \& 4, depicting the pattern in randomly picked data (from 10 years ahead, to the month) and the pattern's resolution increase with lithosphere's responsiveness, respectively. The specific time-slot was selected as the most recent half-a-year span with single alignments only, i.e., without overlapping alignments. 
I 10 C T $\Rightarrow$

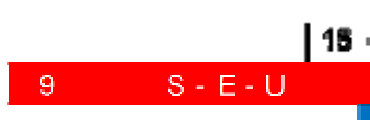

$18 \rightarrow$

I $1 \quad N \circ \vee \Rightarrow$

$16 \quad J-V-E$

10

E- S - Me

I $100 \mathrm{~T}$

| 15 >

I $\mathrm{N}$ ○ $\mathrm{V} \rightarrow$

[16

$U-E-M a$
[18
| $15 \rightarrow$
l 1
D E G $\rightarrow$

\section{F. M. 27}

I 1 F E $B$

$\begin{array}{llll}1 & \text { J } & \mathbf{A} & \mathbf{N}\end{array}$

$\mathrm{E}-\mathrm{V}-\mathrm{Sa}$

\section{| $18 \rightarrow$}

E-Me -

\section{1 J A N $\rightarrow$}

$\mid 18 \rightarrow$

Figure 2. All 11 astronomical alignments longer than 3 days that occurred during the October 2015-March 2016 test-interval, including both sole (unobscured by other alignments) Full Moon alignments from the same interval. The alignments correspond to Figure 1, and were as follows: (a) SunEarth-Uranus, 9-16 October; (b) Jupiter-Venus-Earth, 16 October-8 November; (c) Earth-Sun-Mercury, 10-20 November; (d) Venus-Earth-Uranus, 18 November-4 December; (e) Earth-Sun-Saturn, 29 November-8 December; (f) Uranus-Earth-Mars, 8-23 December; (g) FullMoon (Sun-Earth-Moon), 24 27 December; (h) Earth-Venus-Saturn, 1-18 January; (i) Earth-Mercury-Sun, 11-22 January; (j) Full Moon (Sun-Earth-Moon), 23-26 January; (k) EarthSun-Neptune, 30 January-9 March. Digital astronomical applet used for determining the alignments was created by Osamu Ajiki of www.astroarts.co.jp. Detailed info can be found at www.seismo.info. 


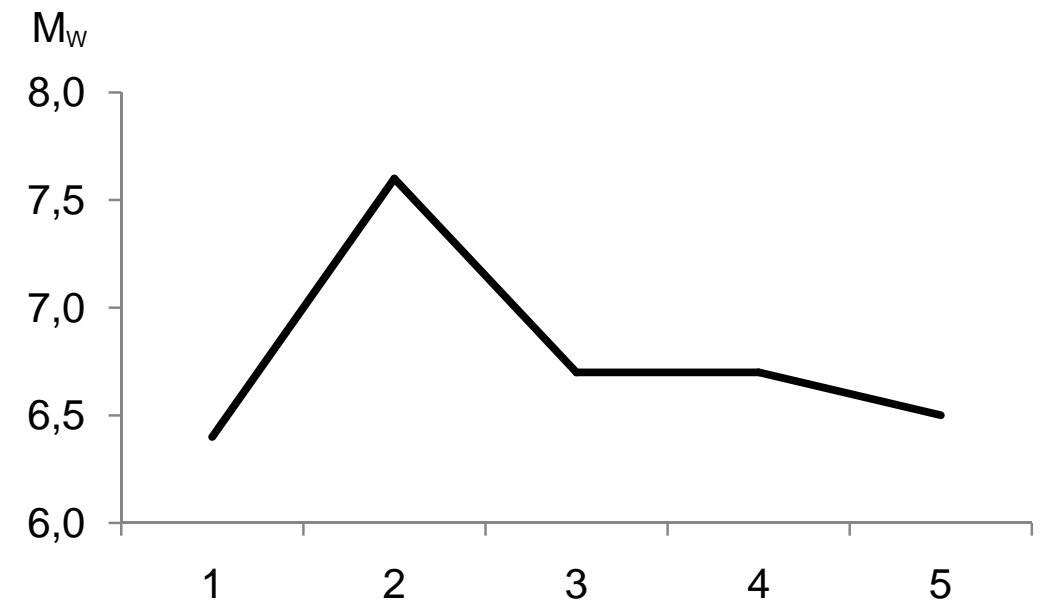

\begin{tabular}{cccccccc} 
& $\mathrm{M}_{\mathrm{w}}$ & date & time GMT & \multicolumn{2}{c}{ USGS EMSC GFZ } & location \\
1 & 6.4 & 31.3 .2006 & $13: 21: 00$ & 6.5 & 6.3 & 5.9 & New Zealand \\
2 & 7.6 & 20.4 .2006 & $23: 25: 03$ & 7.6 & 7.7 & 6.6 & Russia \\
3 & 6.7 & 29.4 .2006 & $16: 58: 05$ & 6.6 & 6.8 & 6.2 & Russia \\
4 & 6.7 & 30.4 .2006 & $19: 17: 16$ & 6.7 & 6.7 & 5.9 & Chile \\
5 & 6.5 & 30.4 .2006 & $21: 40: 58$ & 6.5 & 6.5 & 5.8 & Chile
\end{tabular}

Figure 3. The pattern as revealed during a randomly selected astronomical alignment (of one decade ahead of the alignments in the rest of this report), Sun-Venus-Uranus, from 31 March-1 May 2006.
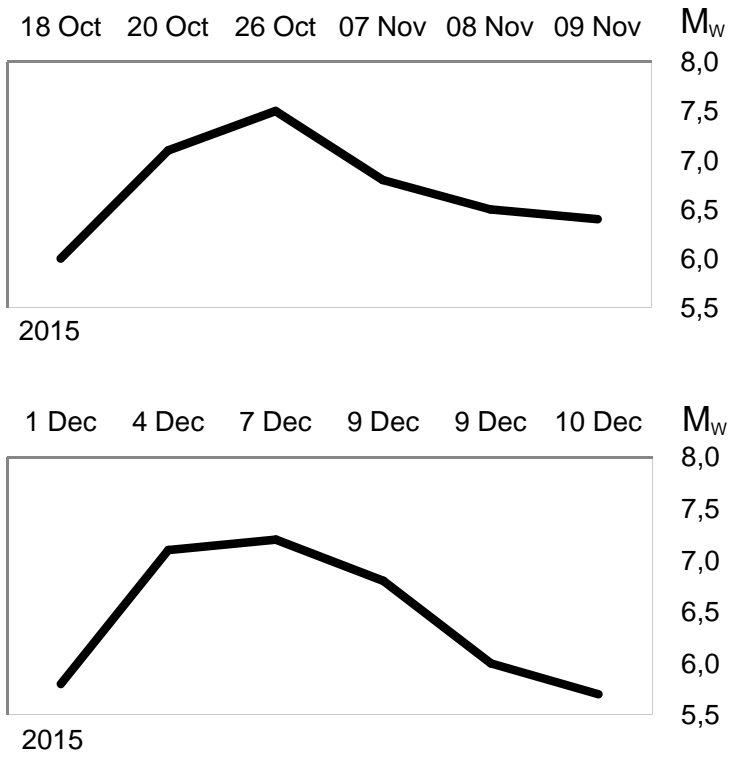

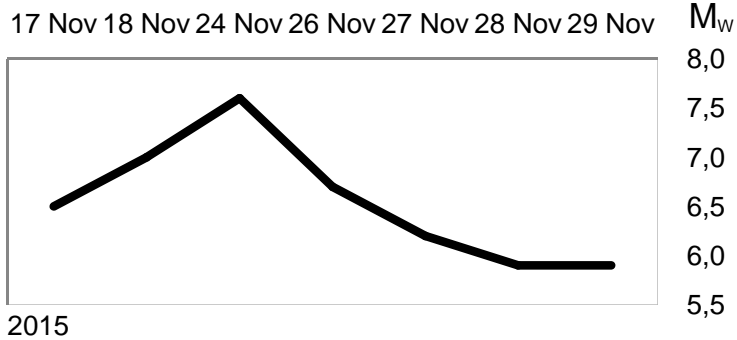

27 May 27 May 28 May 28 May 31 May 31 May31 May $M_{w}$

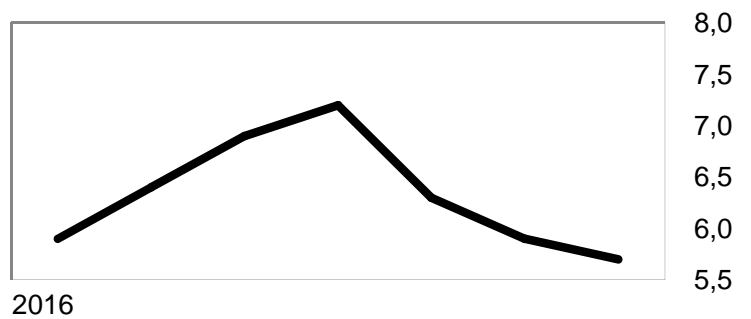

Figure 4. The pattern gets better resolved with increase in occurrence of M6.3+ earthquakes: top left panel, during Jupiter-Venus-Earth alignment of October-November 2015; top right, during VenusEarth-Uranus alignment of November 2015; bottom left, during Earth-Sun-Saturn alignment of December 2015; bottom right, during Earth-Sun-Venus alignment of May-June 2016. 


\section{New yet old}

The fact that the Earth itself has to be a part of an extraterrestrial geophysics theory (as in that case the Earth too is an external cause of seismicity to other heavenly objects) renders the previous considerations mentioned at the beginning somewhat correct as well. This may come as a surprise to a scientist used to categorical either-or and/or signal-to-noise approaches. But it is not that those alternatives were all incorrectly posited (or else they would not have endured for so long and kept receiving independent confirmations); rather, the problem with most of those old ways was in their looking from the "wrong" end.

Thus tackling geophysics problems from extrabodily point of view should rely on previous knowledge such as the above-mentioned alternatives, instead of discarding such attempts altogether. For example, from the extraterrestrial point of view the ionosphere's alleged precursory quality stems not from a mysteriously ejected gas from deep interior upward in a highly concentrated fashion (laser-like), which then equally mysteriously gets injected into the extremely turbulent atmosphere where it wishfully stays locked over the future epicenter for days - but from Space instead, and then along the vector of secondary tidal forcing down onto and into the Earth and vicinity. Similarly, an important indicator that a new physics based on the here revealed mechanism is nigh comes from compelling reports on sunspot activity suppressing ionosphere's spread- $E_{s}$ up to 3 days prior to strong earthquakes (Liperovsky, et al., 2005). Examples like the above two are numerous indeed, so that new physics ought to relate strong quakes to activity of the stars and beyond. At any rate, Earth energy budget and tectonics are mostly due to astrophysical and not geophysical reasons. Since planarity is a necessary condition for any aligning to take place, the near coplanarity of planets - arguably regarded as odd for our own solar system - is in fact a necessary condition for active geophysics as a life-supporting system.

Implications of the pattern discovery for earthquake prediction are fundamental, and require amending of the prediction's conventional all-or-nothing definition and requirements for positive forecasting. Akin to a discovery of medicine for a previously terminal disease, which can control the disease but still not cure it, the improvement here is comparatively significant as well. And as for negative forecasts (in terms of dates without any M6.3+ seismicity whatsoever), those are now possible in the classical all-or-none sense years ahead for quiescent intervals, as well as for the most part of an alignment once it commences, in most cases. This will have significant societal impact via saving of life and property, lowering of risk to insurance industry, more efficient health-care management, safer nuclear and other critical facilities and operations like transport of sensitive materials, to name a few.

\section{Acknowledgments}

Author credits Petr Vaníček for first noticing periodicity of spectra from superconducting gravimeter's weekly data and correlation with certain earthquakes, and Will Featherstone for first noticing 3-day precursory quality of data; and thanks Barbara Romanowicz for comments and Jeffrey Park for suggestions. 


\section{Bibliography}

Baker R. G.V., and Flood P. G. (2015) The Sun-Earth connect 3: lessons from the periodicities of deep time influencing sea-level change and marine extinctions in the geological record, SpringerPlus 4:285.

Crespi M., Cuffaro, M., Doglioni, C., Giannone, F., and Riguzzi, F. (2007) Space geodesy validation of the global lithospheric flow, Geophys. J. Int. 168: 491-506.

Den Hartog J. P. (1985) Mechanical vibrations. New York : Dover publications, $4^{\text {th }}$ ed.

Ellsworth W. L., and Beroza G. C. (2005) Seismic evidence for an earthquake nucleation phase, Science 268: 851-855.

Fielder G. (1974) Local b-values related to seismicity, Tectonophysics 23: 277-282.

Heki K., and Enomoto Y. (2015) Mw dependence of the preseismic ionospheric electron enhancements, J. Geophys. Res. Space Phys. 120: 7006-7020.

Heki K. (2011) lonospheric electron enhancement preceding the Tohoku-Oki earthquake, Geophys. Res. Lett. 38: L17312.

Ihmlé P., and Jordan T. H. (1994) Teleseismic search for slow precursors to large earthquakes, Science 266: 1547-1551.

Iorio L. (2015) Gravitational Anomalies in the Solar System? Int. J. Mod. Phys. D24: 1530015, invited review.

Jacoby W. R. (2001) Successes and failures in geodynamics: from past to future, J. Geod. 32: 3-27.

Liperovsky V. A., Meister, C.-V., Liperovskaya, E., Vasil'eva, N. E., and Alimov, O. (2005) On spreadEs effects in the ionosphere before earthquakes, Nat. Haz. Earth Sys. Sci. 5: 59-62.

Menke W. (1989) Geophysical data analysis: discrete inverse theory, In: Dmowska R and Holton J R., Int. Geophys. Series 45.

Omerbashich M. (2011) Astronomical alignments as the cause of M6 seismicity, arxiv prepirnt, Cornell University Library, http://arxiv.org/abs/1104.2036.

Omerbashich M. (2006) Gauss-Vanícek Spectral Analysis of the Sepkoski Compendium: No New Life Cycles, Comp. Sci. Eng. 8:26-30. Erratum due to journal error in: Comp. Sci. Eng. 9 (4):5-6.

Omerbashich M. (2012) Hyperresonance Unifying Theory and the resulting Law, J. Eur. Roy. Soc. 1: 5-11, https://hal.archives-ouvertes.fr/hal-00808674.

Omerbashich M. (2007) Magnification of mantle resonance as a cause of tectonics, Geodyn. Acta (Eur. J. Geodyn.) 20: 369-383.

Omerbashich M. (2015) Milky Way does not cause periodic mass extinctions on Earth (Reply to: Baker, R.G.V., Flood, P.G. (2015), SpringerPlus 4:285), HAL archive, https://hal.archivesouvertes.fr/hal-01184503. 
Omerbashich M. (2015) Theoretical value of Newtonian constant G confirmed by the International Bureau of Weights \& Measures in Paris, J. Eur. Roy. Soc. 1: 3-4, https://hal.archives-ouvertes.fr/hal01101940.

Schröder W., and Treder H.-J. (1997) Einstein and geophysics: Valuable contributions warrant a second look, Eos Trans. AGU 43 (78): 479-485.

Smith W. D. (1986) Evidence for precursory changes in the frequency magnitude b-value, Geophys. J. Roy. Astr. Soc. 86: 815-838.

Smith W. D. (1981) The b-value as an Earthquake Precursor, Nature 289: 136-139.

Stevenson D.J. (2008) A planetary perspective on the deep Earth, Nature 451: 261-265.

Suda N., Nawa K. and Fukao Y. (1998) Earth's background free oscillations, Science 2089 (279).

Tamrazyan G. P. (1968) Principal regularities in the distribution of major earthquakes relative to solar and lunar tides and other cosmic forces, Icarus 3 (1): 574-592.

Turcotte D. L., and Schubert G. (2002) Geodynamics. Cambridge University Press, $2^{\text {nd }}$ ed.

Wyss M. (1973) Towards a physical understanding of the earthquake frequency distribution, Geophys. J. Roy. Astr. Soc. 31: 341-359. 